\title{
EFEKTIFITAS LATIHAN ABDOMINAL STRETCHING TERHADAP INTENSITAS NYERI HAID (DISMENOREA) PADA REMAJA PUTRI
}

\author{
Rosita $^{1}$, Nurul fitri Sugiarti Syam ${ }^{2}$, Ayu Lestari ${ }^{3}$ Jumrah $^{4}$ \\ Universitas Megarezky ${ }^{1234}$ \\ e-mail: ${ }^{1}$ rositapasse88@gmail.com, ${ }^{2} N f s s a g y . g y @ g m a i l . c o m,{ }^{3}$ ayulestari161073@gmail.com, \\ ${ }^{4}$ jumrah.mega.rezky@gmail.com
}

\begin{abstract}
Menstrual pain (dysmenorrhea) is one of the menstrual disorders that most women experience in adolescents. With one of the nonpharmacological practice stretching techniques can be done with the goal of knowing if there is an application effect on the intensity of menstrual pain (dysmenorrhea) in adolescents women. The type of research is an experimental design with the design approach used is the pre test- post test control group design, which is done in SMKN 01 makassar 2020 with 32 people research respondents, according to the two-split criteria for interagency and control groups as the pre-and post data processing technique on each group. Based on data normality tests, non-distribution of normal results, the tests used were wilcoxon tests. Furthermore, the pre-post normality test of unregulated data control interventions using the mann-whitney test.Research shows that test results on the pre post interventions using wilcoxon tests came p value $(0,000<0.05)$. control groups using mannwhitney tests got $p$ value $(0,000<0.05)$. Thus it may be determined that there is an intermediate effect on the intensity of menstrual pain (dysmenorrhea).Based on the results of this study is expected for all elements that include educational agencies, subsequent researchers, teenagers and communities are able to provide information about abdominal tracks exercises as non-pharmacological therapy to reduce the intensity of hairsty pain (dysmenornea).
\end{abstract}

Key words: menstrual pain; dysmenorrhea; Abdominal Stretching Exercise

\begin{abstract}
ABSTRAK
Nyeri Haid (dismenorea) merupakan salah satu gangguan menstruasi yang banyak dialami oleh wanita terutama pada remaja. Dengan salah satu terapi nonfarmakologis tehnik latihan abdominal stretching dapat dlakukan dengan tujuan untuk untuk mengetahui apakah ada pengaruh latihan abdominal stretching terhadap intensitas nyeri haid (dismenorea) pada remaja putri. Jenis penelitian adalah quasi eksperimen dengan desain pendekatan yang digunakan adalah pre test- post test control group desain, yang mana penelitian ini dilakukan di di SMKN 01 makassar tahun 2020 dengan jumlah responden penelitian 32 orang, sesuai dengan kriteria inklusi yang terbagi dua yaitu kelompok intervensi dan kelompok kontrol adapun tehnik pengolahan data pre dan post pada masing masing kelompok. berdasarakan hasil uji normalitas data, tidak berdistribusi normal sehingga uji yang digunakan adalah uji wilcoxon. Selanjutnya hasil uji normalitas pre-post kelompok intervensi kontrol data tidak berdistribusi normal sehingga menggunakan uji Mann-Whitney. Hasil penelitian menunjukkan bahwa hasil uji padakelompok pre post intervensidengan menggunakan uji Wilcoxon didapatkan nilai $\mathrm{p}$ value $(0.000<0.05)$ kelompok intervensi control dengan menggunakan uji Mann-Whitney didapatkan nilai $\mathrm{p}$ value $(0.000<0.05)$. Sehingga dapat disimpulkan bahwa ada pengaruh latihan abdominal stretching terhadap intensitas nyeri haid (dismenorea). Berdasarkan hasil penelitian ini diharapkan bagi seluruh elemen yang mencakup instansi pendidikan, peneliti selanjutnya,remaja dan Masyarakat mampu memberikan informasi tentang latihan abdominal stretching sebagai terapi non farmakologis untuk menurunkan intensitas nyeri haid (dismenorea)
\end{abstract}

Kata kunci: Nyeri haid; Dismenorea; Latihan Abdominal Stretching 

Vol. 16 No. 3 September - Desember 2021

\section{PENDAHULUAN}

Masa remaja merupakan suatu fase tumbuh kembang yang dinamis dalam kehidupan seorang individu. Masa ini merupakan periode transisi dari masa kanak-kanak ke masa dewasa yang ditandai dengan percepatan perkembangan fisik, psikologis, emosional, dan sosial (1)

Menstruasi menimbulkan tanda dan gejala yang berbeda, diantaranya gangguan rasa aman atau nyeri. Hampir seluruh perempuan termasuk didalamnya remaja putrid pasti pernah mengalaminya dengan berbagai tingkatan, mulai dari yang pedal-pegal di panggul, rasa keram pada daerah suprapubis, mual muntah, nafsu makan menurun hingga terjadi kehilangan keadaran. (2)

Angka kejadian dismenore di dunia sangat besar lebih dari $50 \%$ perempuan disetiap Negara mengalami dismenore.(3)

Menurut Proverawati, 2009 dismenorea yang banyak terjadi di Indonesia adalah dismenorea primer, presentase dismenorea di Indonesia sebesar 64,25\% yang terbagi dari dismenorea primer sebanyak 54,89\% dan pada dismenorea sekunder sebanyak 9,36\%.(4)

Sekitar 70-90\% kasus nyeri haid terjadi saat usia remaja dan sekitar $10 \%$ remaja yang mengalami nyeri haid akan mempengaruhi aktivitas akademik dan sosialnya. (2)

Dismenore merupakan masalah ginekologis yang paling umum dialami wanitausia remaja. Keluhan yang dirasakan biasanya adalah merasa nyeri pada perut bagian bawahdan menjalar sampai ke punggung serta paha. (5)

Nyeri haid atau dismenorrhoea merupakan "rasa nyeri yang terjadi sebelum atau selama menstruasi yang sangat menyiksa bagi wanita dan hal yang tidak pernah diinginkan oleh wanita(6)

Dismenorea sangat berdampak pada remaja usia sekolah karena menyebabkan terganggunya aktivitas sehari-hari. Jika seseorang siswi mengalami dysmenorea aktivitas belajar mereka di sekolah terganggu dan hal ini membuat mereka tidak masuk sekolah. Seseorang siswi yang mengalami dysmenorea tidak dapat berkonsentrasi belajar dan motivasi bel;ajar akan menurun. Oleh karena itu dismenorea pada remaja harus dapat ditangani dengan tindakan yang tepat untuk menghindari dampak neghatif yang akan timbul (7)

Menurut penelitian Nathan pada tahun 2011, menyatakan bahwa $30-60 \%$ wanita mengalami dismenore, dan 7-15\% tidak dapat pergi ke sekolah atau bekerja. Untuk mengatasi kondisi seperti ini dapat dilakukan dengan terapi farmakologi dan non farmakologi. Terapi nonfarmakologi lebih banyak dipilih karena lebih aman bila dibandingkan dengan terapi farmakologi, salah satunya yaitu abdominal stretching exercise.(8)

Meskipun keluhan nyeri menstruasi umum terjadi pada wanita, sebagian besar wanita yang mengalami nyeri menstruasi jarang pergi ke dokter, mereka mengobati nyeri tersebut dengan obat-obat bebas tanpa resep dokter dan tanpa pengawasan dokter.(9)

Latihan abdominal stretching adalah latihan peregangan dalam pemeliharaan dan mengembangkan fleksibilitas atau kelenturan daerah perut untuk mengurangi intensitas nyerihaid yang dilakukan pada saat dismenore untuk meningkatkan kekuatan otot, daya tahan dan fleksibilitas otot yang dilakukan selama 10 menit(10)

Berdasarkan hasil studi pendahuluan yang dilakukan peneliti di SMKN 01 MAKASSAR tiga tahun terakhir jumlah remaja putri 884 siswi yang terdiri dari kelas X 318 siswi, kelas XI 279 siswi dan kelas XII 247 siswi, salah satu keluhan yang paling sering dirasakan oleh remaja saat menstruasi yaitu nyeri haid (dismenorea) serta melakukan wawancara pada 10 siswi dengan hasil 2 siswi mengalami nyeri haid dan tidak mengerti cara mengatasinya,3 siswi mengatasi nyeri haid dengan minum air hangat, 2 siswi mengalami nyeri haid dan 1 siswi meminum obat pereda nyeri, serta 2 siswi tidak mengalami nyeri haid.

Kejadian ini adalah salah satu alasan siswi tidak hadir dalam proses pelajaran hal ini sangat mengganggu dalam proses belajar mengajar, yang menyebabkan remaja putri sulit berkonsentrasi karena ketidaknyamanan yang dirasakan ketika mengalami nyeri haid, diantaranya yang mempunyai riwayat nyeri haid, didapatkan data bahwa penanganan yang telah dilakukan untuk mengurangi atau menghilangkan nyeri haid cara dengan obat analgesik, dibiarkan saja, tidur, menggunakan aromatherapy, minum air hangat dan menangis sedangkan untuk latihan fisik terutama latihan abdominal stretching tidak pernah dilakukan.

Berdasarkan latar belakang masalah di atas tentang Latihan latihan abdominal stretchingterhadap intensitas nyeri dismenorea pada remaja putri, maka peneliti merumuskan pernyataan "Apakah ada pengaruh latihan abdominal stretching terhadap intensitas nyeri haid (dismenorea) pada remaja putri di SMKN 01 Makassar" sehingga tujuan penelitian ini adalah untuk mengetahui apakah ada pengaruh latihan abdominal stretching terhadap intensitas nyeri haid (dismenorea) 


\section{Jenis penelitian}

Penelitian ini adalah penelitian adalah quasi eksperimen dengan menggunakan rancangan two group pretest- post test control group desain. Penelitian ini dimaksud untuk menggambarkan perbandingan dua kelompok dimana satu kelompok eksperimen di berikan Abdominal Stretching dan satu kelompok lagi tidak di di berikan perlakuan.

Peneliti ini menggunakan lembar observasi yang diisi oleh masing masing responden pada saat menstruasi di hari pertama. Untuk kemudian mengetahui skala nyeri yang dirasakan responden, peneliti menggunakan skala Numeral Rating Scales $(N R S)$ berdasarkan score nyeri yang dirasakan masing masing responden untuk mengetahui tingkatan nyeri pada responden tersebut. Demikian juga setelah melakukan latihan abdominal stretching responden mengisi lembar observasi setelah latihan dengan demikian peneliti dapat membandingkan score nyeri yang dirasakan masing masing responden sebelum dan setelah latihan abdominal stretching. Dengan membandingkan score nyeri yang dirasakan masing masing responden sebelum dan sesudah latihan dapat diketahui pengaruh latihan tersebut terhadap intensitas nyeri haid yang dirasakan oleh responden penelitian.

\section{Populasi dan sampel}

Populasi dalam penelitian ini adalah seluruh siswi kelas XI sebanyak 92 siswi kelas XI jurusan akutansi yang ada pada tahun 2020 di SMKN 01 Makassar yang beralamat di JlnAndi Mangerangi No 38 .

Sampel dalam penelitian ini adalah dengan menggunakan tehnik pemilihan sampel secara purpossif sampling. pada penelitian ini berjumlah 32 orang siswi pada bulan April-Juni tahun 2020 sesuai dengan kriteria inklusi yang ditentukan oleh peneliti.

\section{Analisis data}

Dalam mengelola data penelitian yang telah di peroleh, maka peneliti menggunakan beberapa uji statistic yaitu: Uji statistic deskriptif, untuk memaparkan karakteristik sampel berdasarkan usia, dan data hasil pre test yang telah di lakukan. Sementara untuk analisis bivariat menggunakan uji wilcoxon.

\section{HASIL}

Tabel 1. Karakteristik Usia Responden Siswi SMKN 01 Makassar

\begin{tabular}{|c|c|c|}
\hline USIA & F & $(\%)$ \\
\hline 16 & 23 & 71.9 \\
\hline 17 & 6 & 18.8 \\
\hline 18 & 3 & 9.4 \\
\hline Total & 32 & 100.0 \\
\hline
\end{tabular}

Tabel 1 menunjukkan bahwa dari 32 jumlah responden di peroleh data responden usia yang terbanyak yaitu berusia 16 tahun berjumlah 23 orang
(71,9\%), dan yang terendah yang berusia 18 tahun berjumlah 3 0rang $(9,4 \%)$.

Tabel 2. Skala Nyeri Haid sebelumIntervensi latihan Abdominal Stretching

\begin{tabular}{|c|c|c|c|c|}
\hline \multirow{2}{*}{ Skala Nyeri } & \multicolumn{2}{|c|}{ Kelompok Intervensi } & \multicolumn{2}{c|}{ Kelompok Kontrol } \\
\cline { 2 - 5 } & $\mathrm{N}$ & $\%$ & $\mathrm{~N}$ & $\%$ \\
\hline Ringan & 11 & 68.8 & 11 & 68.8 \\
\hline Sedang & 5 & 31.2 & 5 & 31.2 \\
\hline Total & 16 & 100.0 & 16 & 100.0 \\
\hline
\end{tabular}

Tabel 2 menunjukkan bahwa Skala nyeri haiduntuk kelompok Intervensi dan kontrol sebelum latihan, skala nyerinya sama yaitu rata rataskala nyeri haid (dismenorea) yang dirasakan oleh siswi adalah berada pada kategori nyeri ringan yaitu 11 siswi dengan persentase $68,8 \%$ dan kategori sedang yaitu 5 siswi atau $31,2 \%$.

Tabel 3. Skala Nyeri Haid setelah Intervensi latihan Abdominal Stretching

\begin{tabular}{|c|c|c|c|c|}
\hline \multirow{2}{*}{ Skala Nyeri } & \multicolumn{2}{|c|}{ Kelompok Intervensi } & \multicolumn{2}{c|}{ Kelompok Kontrol } \\
\cline { 2 - 5 } & $\mathrm{N}$ & $\%$ & $\mathrm{~N}$ & $\%$ \\
\hline Ringan & 16 & 100.0 & 12 & 75.0 \\
\hline Sedang & 0 & 0 & 4 & 25.0 \\
\hline Total & 16 & 100.0 & 16 & 100.0 \\
\hline
\end{tabular}

Table 3 menunjukkan bahwa skala nyeri haiduntuk kelompok Intervensi setelah latihan, skala nyeri semua siswi pada kategori ringan sedangkan untuk kelompok control rata rataskala nyeri haid (dismenorea) yang dirasakan oleh siswi adalah berada pada kategori nyeri ringan yaitu 12 siswi dengan persentase $75 \%$.

Tabel 7. Uji Wilcoxon kelompok intervensi

\begin{tabular}{|c|c|c|c|c|c|}
\hline \multicolumn{2}{|c|}{ Kelompok intervensi } & $\mathrm{N}$ & $\begin{array}{c}\text { Mean } \\
\text { Rank }\end{array}$ & $\begin{array}{c}\text { Sum } \\
\text { of } \\
\text { Ranks }\end{array}$ & $\begin{array}{c}\text { Nilai } \\
\mathrm{p}\end{array}$ \\
\hline $\begin{array}{c}\text { Post } \\
\text { intervensi } \\
\text { Pre } \\
\text { intervensi }\end{array}$ & Menurun & 16 & 8.50 & 136.00 & \\
\cline { 2 - 5 } & Meningkat & 0 & .00 & .00 & \multirow{2}{*}{0.000} \\
\cline { 2 - 5 } & Menetap & 0 & & & \\
\cline { 2 - 5 } & Total & 16 & & & \\
\hline
\end{tabular}

Pada tabel 7. terlihat bahwa reponden yang mengalami penurunan tingkat nyeri haid sebanyak 16 orang, tidak responden yang mengalami peningkatan nyeri dan mengalami nyeri yang menetap. Analisis dengan uji wilcoxon didapatkan nilai $\mathrm{p}=0,000<0,05$ hal ini menunjukan bahwa terdapat pengaruh latihan abdominal stretching terhadap intensitas nyeri haid.

Tabel 8. Uji Wilcoxon kelompok kontrol 

Vol. 16 No. 3 September - Desember 2021

\begin{tabular}{|l|c|c|c|c|c|}
\hline \multicolumn{2}{|c|}{ Kelompok kontrol } & N & $\begin{array}{c}\text { Mean } \\
\text { Rank }\end{array}$ & $\begin{array}{c}\text { Sum of } \\
\text { Ranks }\end{array}$ & Nilai p \\
\hline $\begin{array}{l}\text { Post kontrol }- \\
\text { Pre kontrol }\end{array}$ & Menurun & 2 & 1.50 & 3.00 & \\
\cline { 2 - 5 } & Meningkat & 0 & .00 & .00 & \multirow{2}{*}{0.180} \\
\hline & Menetap & 14 & & & \\
\cline { 2 - 5 } & Total & 16 & & & \\
\hline
\end{tabular}

Pada tabel 8 didapatkan dari 16 orang responden terdapat 2 orang responden yang mengalami penurunan nyeri haid, tidak ada yang mengalami peningkatan dan 14 responden mengalami nyeri yang menetap. Hasil uji bivariat didapatkan nilai $\mathrm{p}=0,180$ $>0,05$ artinya tidak ada pengaruh pada kelompok kontrol.

\section{PEMBAHASAN}

Pada Kelompok Intervensi, yang diberikan latihan abdominal stretching terjadi penurunanan intensitas nyeri haid (dismenorea) berdasarkan hasil observasi yang didisi oleh masing masing responden didapatkan intensitas nyeri haid atau keparahan nyeri mengalami penurunan hal ini disebabkan terjadinya peningkatan oksigenasi dalam sel sehingga otot uterus yang berkonteraksi dan otot panggul yang mengalami ketegangan menjadi rileks.

Tujuan latihan peregangan otot adalah membantu meningkatkan oksigenasi atau proses pertukaran oksigen dan karbon dioksida didalam sel serta menstimulasi aliran drainase sistem getah bening, sehingga dapat meningkatkan kelenturan otot dengan cara mengembalikan otot-otot pada panjangnya yang alamiah dan dapat memelihara fungsinya dengan baik serta memperbaiki elastisitas atau fleksibilitas jaringan tubuh serta mengurangi kram pada otot.(11)

Pada kelompok kontrol yang mana kelompok ini tidak melakukan latihan abdominal stertching. Berdasarkan observasi pre kontrol dan post kontrol kelompok initerdapat siswi yang menunjukan perubahan nyeri sebanyak dua orang dengan intersitas nyeri menurun karena dengan alih posisi dan beberapa hiburan, namundalam kelompok kontrol ini didapatkan rata rata intensitas nyeri haid dengan skala nyeri tetap.

Latihan ini sangat mudah dilakukan, sederhana, ekonomis dan dapat dirasakan perubahan intensitas nyeri haid (dismenorea).Secara keseluruhan responden kelompok intervensi, semua menunjukkan adanya pengaruh penurunan intensitas nyeri setelah diberikan tekhnik latihan abdominal stretching.

Asumsi dari peneliti bahwa nyeri haid yang dirasakan masing masing respoden dipengaruhi oleh faktor yang berbeda beda. Banyak usaha atau metode yang dapat dilakukan untuk penaganan nyeri haid (dismenorea) yaitu dengan terapi farmakologi dan non farmakologi dalam penelitian ini, peneliti menggunakan latihan abdominal stretching yang yang temasuk dalam terapi nonfarmakologi. Berdasarkan hasil Observasi sebelum dan sesudah latihan pada kelompok intervensi yang melakukan latihan abdominal strething terdapat penurunan intensitas nyeri haid dibandingkan pada kelompok kontrol tidak terdapat penurunan intensitas nyeri.

\section{KESIMPULAN}

Ada pengaruh latihan abdominal stretching terhadap intensitas nyeri haid (dismenorea)pada kelompok intervensi dan Terdapat perbandingan yang signifikan antara kelompok intervensi yang melakukan latihan abdominal stretching dan yang tidak melakukan latihan

\section{DAFTAR PUSTAKA}

1. Prawirohardjo S. KANDUNGAN. Cetakan Ke. Anwar Mochamad, editor. Angewandte Chemie International Edition, 6(11),. PT. Bina Pustaka Sarwono Prawirohardjo; 2014. 951-952 p.

2. Hidayah N. PENGARUH ABDOMINAL STRETCHING EXERCISE TERHADAP PENURUNAN DISMENORE PADA SISWI REMAJA DI. 2017;(February):954-63.

3. Kusuma IO. Pengaruh Abdominal Streching Exercise dan Relaksasi Nafas dalam Terhadap Penurunan Skala Nyeri Dismenore. Kementeri Kesehat RI. 2019;1-63.

4. Windastiwi W, Pujiastuti W. PENGARUH ABDOMINAL STRETCHING EXERCISE TERHADAP. 2017;6(12):17-26.

5. Bd F, Rizki H, Handini S, Dita R. Pengaruh Abdominal Stretching Exercise Terhadap Penurunan Intensitas Nyeri Haid Pada Remaja Putri Effect of Abdominal Stretching Exercise For Reducing Menstrual Pain The Intensity of Adolescent Girl. 2019;3(2):68-73.

6. Vidia PA. Pengaruh pemberian latihan abdominal stretching terhadap tingkat nyeri haid ( dysmenorrhoea ) pada siswi kelas $\mathrm{x}$ dan xii smkn 3 malang. 2011;4681:67-76.

7. Silviani YE, Rosnita T, Keraman B. PENGARUH ABDOMINAL STRETCHING EXERCISE TERHADAP PENURUNAN DYSMENORRHEA THE EFFECT OF ABDOMINAL STRETCHING EXERCISE ON DYSMENORRHEA REDUCTION. 2020;7(1):58-62.

8. Mey F. PENGARUH LATIHAN A BDOMINAL STRETCHING DAN MUSIK KLASIK TERHADAP INTESITAS NYERI HAID PADA REMAJA PUTRI. 2018;9(2):133-8. 
9. Ety. Pengaruh Abdominal Strethcing Exercise Terhadap Dismenore Primer. 2009;1-13.

10. Puspita L, Anjarwati T. Wellness and healthy magazine. 2019;1:215-22.

11. Yumnunnisak. Pengaruh Abdiminal Streching Terhadap Intensitas Nyeri Haid pada Remaja Putri. 2018. 